\title{
When biology goes underground: genes and the spectre of race $^{1}$
}

\author{
TIM INGOLD ${ }^{2}$
}

\begin{abstract}
This paper examines the changing meanings of the concept of 'biology', and of its opposition to 'culture', through an analysis of the ways in which anthropologists have sought to refute the idea that humanity is divided into distinct races. Efforts to redefine all extant humans as belonging to a single sub-species, or to replace 'race' with 'culture', only serve to perpetuate raciological thinking. This kind of thinking had its origins in the moral evaluation of physical difference, the construction of hierarchy and essentialist typology. In its 1996 'Statement on Race', the American Association of Physical Anthropologists ruled out any connection between the biological and cultural characteristics of human beings. Yet the statement is internally inconsistent in the meanings it attributes to both biology and culture. These shifts in meaning correspond to phases in the history of anthropology, identified here as the Enlightenment phase (culture as a process of civilisation drawing on universal biopsychological capacities), the Consensual phase (culture as diverse traditions inscribed upon a common biological substrate) and the Interactionist phase (behaviour as the product of an interaction between culturally and genetically transmitted information in a given environment). The paper seeks an alternative, relational approach that focuses on the dynamics of developmental systems. Only through such an approach, it is argued, can we wrest biology away from the combination of geneticism and essentialism that continues to perpetuate the logic of raciology even in the course of its vehement denial.
\end{abstract}

\section{Introduction}

For some years now, and along with many anthropological colleagues, I have been seeking a way of understanding the relations between human beings and their environments that allows us to overcome the separation, so deeply entrenched in western thought and science, between the world of nature and the world of human society. ${ }^{3}$ This also means trying to overcome the division in the way we tend to see ourselves, as social beings or persons on the one hand, and as biological organisms, members of a particular species, on the other. The problems we face are formidable. Much of the difficulty stems from the inherent 'slipperiness' of our concepts, and none are more slippery than the concepts of biology and culture. To introduce the problem, I want to begin by unpacking what has surely been one of the most sensitive notions in the whole history of anthropology, namely that of 'race'. Most academic disciplines are proud of their history, and like to trace their origins to the work of great scholars of the past. Anthropologists are less fortunate, for there is no getting around the fact that the discipline owes its origins, very largely, to the virulent racism of the late nineteenth century. ${ }^{4}$ There was a period, from around 1870 to 1920 , when anthropology quite explicitly identified itself as the study of the different races of mankind. Indeed this is still how the subject is often popularly portrayed. For today's 
anthropologists, however, this image is a source of continuing embarrassment. They would like to put it behind them, once and for all. Yet somehow the spectre of race continues to haunt them.

One reason for this is obvious: we live in a world in which racism is still rampant, so that as students of society we have to confront the questions of what people mean by race, why the idea still exercises such a hold on the imagination, how it shapes attitudes towards the self and others, and how these, in turn, bear upon the experience of social life. But there is another reason which, for anthropologists, is rather less comfortable. It is that the arguments they have used to refute the idea that humanity is divided into distinct races still carry with them the germs of the very kind of thinking they claim to demolish. ${ }^{5}$

By and large, anthropologists have tried to deal with the problem of race in two ways. The first is by declaring that all humankind comprises just one race or sub-species, Homo sapiens sapiens, all other sub-species (such as the ill-fated Neanderthals) having long since been reduced to extinction. But does this amount to an acknowledgement that race does not exist? Far from it. To say that all humans are of one race is not to dismiss the concept of race itself, but rather to confirm it. It is to claim not just that race exists, but that in the prehistoric past - though no longer today - there were indeed distinct races of mankind. The story that is told by modern science, of how superior creatures of our own race, Homo sapiens sapiens (or 'anatomically modern humans', as they are known by specialists), spreading north from Africa, overran the continent of Europe at the expense of its indigenous Neanderthal population, is almost a precise mirror image of the nineteenth century story of the how white Europeans were destined to colonise and subjugate the 'primitive races' of black Africa. ${ }^{6}$ What the new story has in common with the old is the belief in a shared essence, or common human nature, that makes us what we are, coupled with the notion that this essence is passed on genealogically - that is, by descent.

Nor is this combination of essentialism and genealogical thinking in any way shaken by the second way in which modern anthropology has tackled the problem of race, that is by simply replacing the word 'race' with the word 'culture'. Instead of saying that humanity is divided into distinct races, anthropological orthodoxy swung to the view that it is divided into distinct cultures, superimposed upon a human nature that is common to all. ${ }^{7}$ But the logic of this division remains precisely the same; only the mechanism of genealogical transmission has been changed - from genetic inheritance to social learning. Thus the reasons that anthropologists latterly adduced for the existence of separate cultures - namely, that the members of a culture share a common essence or heritage that is passed on by descent - would, if applied in the realm of biological variation, lead straight back to the existence of race. The problem for contemporary anthropology is that any critique of the concept of race that would really carry conviction would, at one and the same time, have to be a critique of the concept of culture as well. We cannot have it both ways, both rejecting the idea of race while holding on to the idea that humanity is segmented into discrete cultures. For the reasons why races don't exist are also the reasons why cultures don't exist. ${ }^{8}$ 


\section{From race to raciology}

But I have run ahead of myself. We need to take a step back, to discover how the idea of race came to be so deeply embedded in the political and intellectual milieu within which anthropology first took shape as a distinct discipline. Of course, like all concepts that touch a raw nerve in human history, race has meant many things to many people. Yet for anyone who still believes that concepts are immaterial, or that arguments about concepts are mere word-play for academics, divorced from the struggles of the real world, the invidious role that notions of race have played in the history of humanity must surely prove otherwise. 'The race concept', as anthropologist Eric Wolf puts it, 'has presided over homicide and genocide'. ${ }^{9}$ One might add that the concept of culture has had historical consequences that are scarcely less devastating, as we have seen in recent movements of 'ethnic cleansing'. It is indeed worth reflecting on the reasons why those who are adamant in their rejection of the race concept are nevertheless happy to embrace the concept of culture, on almost exactly the same terms.

The etymological source of the word 'race' has been traced - albeit somewhat inconclusively - to the Latin generare (to beget) and generatio (generation). The root meaning is one of common descent, or shared genealogical origin. It is in this sense that, at least until quite recently, one could often find authors - for example of popular travel books - talking about the 'races of men' inhabiting this territory or that country, in much the same sense that we might now talk about nations, cultures, peoples or ethnic groups. And in the same sense, race is still popularly used as a synonym for species, as in 'the human race'. Usages of this kind, though perhaps rather loose, are relatively harmless. However in the eighteenth and nineteenth centuries, during the heyday of European colonial expansion, the notion of race gathered additional connotations that converted it from a merely descriptive term into one that carried an exceedingly potent moral and political charge.

Roughly speaking, these connotations had their origins in three lines of thought:

i) It was supposed that people's physical appearance or type was an index of their temperament or moral disposition, so that one could read off what people were like - good or bad, honest or crafty, intelligent or stupid, active or passive - from the way they looked.

ii) It was assumed that different types could be arranged in a single hierarchy from inferior to superior, such that higher races would inevitably win out in what came to be seen as a 'struggle for existence'.

iii) Every race was thought to represent a type in the strict sense: that is to say, for each race there was supposed to correspond an essential form of the human being - Caucasoid, Mongoloid, Negroid, and so on - to which every living individual represented a more or less close approximation.

These three tendencies - the moral evaluation of physical difference, the construction of hierarchy, and essentialist typology - were together responsible for the climate of 
racism within which the discipline of anthropology emerged and which is now a source of such shame.

Modern scholarship, of course, claims to have shown that the underlying assumptions of racist thinking, or of what Wolf calls 'raciology', ${ }^{10}$ have no scientific credibility. First of all, racial essentialism - the belief that human beings come in a number of fixed 'racial types' - was shown to be incompatible with Darwinian evolutionary theory. Modern evolutionary biologists are concerned not with the enumeration of distinct types but with the mapping of genetic distributions. For any particular gene or characteristic, this map resembles the kind of chart we see every day on the television weather forecast, showing tomorrow's expected temperatures. The lines on the chart are contours indicating temperature gradients; they are not absolute boundaries between hot and cold. Likewise, genetic distribution maps use contours to depict graded variations in the percentage of the population that carries a particular character. But for every character you might select, the map looks quite different. If you were to superimpose maps for a range of different characters, then you would find no neat correspondence but an apparently chaotic tangle of intersecting gradients. There is, then, no basis for a division of humankind into defined sub-groups on the basis of hereditary characteristics.

This point seems incontrovertible. Moreover there is no evidence to suggest that extant human populations can be ranked in terms of any criterion of superiority or inferiority. Consider for example the hotly disputed criterion of intelligence. Are some populations more intelligent than others? The majority of contemporary anthropologists would, I think, take the view that there is no way of measuring intelligence that is not culture-bound. If children from other cultures do badly in intelligence tests devised by western psychologists and educationalists, this is simply because the ways in which the problems are set, and indeed the whole institutional apparatus of the 'test' with its attendant technologies and authority structures, are alien to their experience. ${ }^{11}$ Many anthropologists would probably want to go even further, to claim that the very notion of intelligence is an invention of western discourse, and that it corresponds to nothing real that could be objectively measured. I myself am of this opinion.

But let us suppose - just for the sake of argument - that there is such a thing as intelligence, and that you can use standard testing procedures to measure it. There still remains the question of the extent to which a person's intelligence is a function of genetic inheritance on the one hand, or, on the other, of the environmental circumstances in which he or she was brought up. Again, most anthropologists would be inclined to place more emphasis on nurture than nature, though for my part I think the whole nature/nurture debate is misconceived. (Later on, I shall explain why.) However, even if it really were the case that a person's level of intelligence is genetically determined, that would still not mean that intelligence varied by race. For this to be so there would have to be significant differences in average intelligence between populations. Although suggestions to this effect have been made from time to time, ${ }^{12}$ there is no evidence whatever to support them. And even if such evidence could be adduced, it would rest on so many undemonstrable assumptions - namely 
that intelligence exists, that it can be measured by standard tests, and that it has a significant innate component - as to be virtually meaningless.

\section{Biology, culture and the 'statement on race'}

A much more tricky problem, however, turns on the issue of the relation - or rather the lack of it - between the biological or physical characteristics of human beings and those aspects of morality, temperament and behaviour that are generally bracketed under the rubric of 'culture'. Right from the early decades of the twentieth century, the absolute separation of biological variation and cultural difference has been central to the anthropological refutation of raciology. In 1930 the acknowledged founder of American cultural anthropology, Franz Boas, declared unequivocally that 'any attempt to explain cultural form on a purely biological basis is doomed to failure'. ${ }^{13}$ So far as most anthropologists were concerned, that was that. This separation or detachment of the cultural from the biological dimensions of human being effectively split anthropology itself into the two quite distinct divisions of physical (or biological) anthropology on the one hand, and social (or cultural) anthropology on the other. Ever since, biological and sociocultural anthropologists have proceeded quite independently of one another - addressing apparently different problems, collecting different kinds of data and speaking different conceptual languages.

The present consensus, on both sides of this academic divide, is summed up in the formal 'statement on race' recently adopted by the American Association of Physical Anthropologists. There is, according to this statement, absolutely no connection between the biological and cultural characteristics of human beings. The crucial passage is reproduced in full below:

There is no necessary concordance between biological characteristics and culturally defined groups. On every continent, there are diverse populations that differ in language, economy, and culture. There is no national, religious, linguistic or cultural group or economic class that constitutes a race. However, human beings who speak the same language and share the same culture frequently select each other as mates, with the result that there is often some degree of correspondence between the distribution of physical traits on the one hand and that of linguistic and cultural traits on the other. But there is no known causal linkage between these physical and behavioural traits, and therefore it is not justifiable to attribute cultural characteristics to the influence of genetic inheritance. ${ }^{14}$

Evidently the intent of the statement is to draw a line under the whole issue: to make it clear, once and for all, that whatever biological differences may exist between people, they are of absolutely no consequence so far as their acquisition of culture is concerned. Unfortunately however, as I shall show, the statement is largely incoherent. And the source of the incoherence lies in fundamental ambiguities surrounding the meanings of both 'biology' and 'culture'.

A glance through the recent (and not so recent) literature reveals a host of different senses of biology and the biological, some of them mutually compatible, others 
directly contradictory. ${ }^{15}$ They can be reduced, however, to five, which I summarise below. Biology can mean:

i) A focus on the basic capacities and dispositions that humans have in common with other animals (especially non-human primates).

ii) A search for what is universal to the human species rather than variable between populations.

iii) An emphasis on the behaviour of individuals rather than higher-order social groupings.

iv) A Darwinian explanatory paradigm of adaptation under natural selection, or some cultural analogue of the same.

v) A concern with the discovery of genetic, as opposed to learning-transmitted, influences on behaviour.

If we return to the 'statement on race', it appears to set out from the third of these senses of the biological. Let me pause to explain this sense a little further. It has long been conventional, in social and cultural anthropology, to suppose that the members of a society or community are united by their possession of a common culture - that is, by a shared corpus of rules and meanings. The limits of sharing, then, were thought to define the limits of society. Thus culture came to be seen as an essentially collective phenomenon, as a property of a higher-level entity, namely society, with an existence and a form of consciousness of its own, over and above the level in which human beings exist as individual organisms. As everything cultural was, so to speak, 'creamed off' to this higher level, the individual was left as a residually biopsychological entity. From this logic stemmed the idea that biologists and psychologists study individuals, while anthropologists and sociologists study groups. There seems to be something inherently 'groupy' in our thinking about society and culture, and something inherently individualising in our thinking about minds and organisms. ${ }^{16}$ And this thinking seems to be confirmed in the first sentence of the passage I cited from the 'statement on race', which asserts that 'there is no necessary concordance between biological characteristics and culturally defined groups'. If groups are defined by their possession of shared culture, then 'biological characteristics' must belong to individuals.

But the statement then carries on to make a distinction between 'physical traits on the one hand and ... cultural traits on the other'. This is to move to another (and in the history of American anthropology, earlier) notion of culture as a property of individuals, now distinguished from biology in terms of a logic of sameness and difference. ${ }^{17}$ Biology is simply taken to mean what all human beings have in common - a sort of 'lowest common denominator' for the species - as distinct from those characteristics in which they differ. This corresponds to the second of the five senses of the biological listed above. For example, it might be argued that the facial gesture we call the smile is found among all humans everywhere: it is therefore a 'biological' or 'physical' trait. The manual gesture of hand-shaking, on the other hand, is by no means universal, so it is assumed to be a 'cultural' trait. Or again, walking is said to be biological, whereas swimming, skating or cycling is cultural. The identification of the biological with what is universal is, of course, a simple corollary of the assumption that, among humans, all difference is due to culture. However as soon as 
we turn to non-human species, which are not supposed to have any culture, that assumption ceases to apply. That is why we end up with the curiously contradictory positions that whereas in the human world, biology is taken to be what makes everyone the same, in the non-human world, biology is supposed to be the source of all variability and difference.

The statement then shifts its terms yet again. It speaks of the difference between 'physical traits' and 'behavioural traits'. So 'culture' is now to be read as 'behaviour'. This shift has to be understood in terms of a distinction that is central to the whole explanatory framework of modern biology: between genotype and phenotype. ${ }^{18}$ The genotype is an underlying programme for constructing an organism of a certain kind, and is thought to be encoded in the materials of heredity, the genes. The phenotype, by contrast, is what we see: the organism as it actually appears to an observer, situated within a particular environment. There are two dimensions to the phenotype: the morphological (the outward form of the organism, what it looks like) and the behavioural (the activity of the organism, what it is observed to do). 'Culture', in the sense that currently concerns us, is simply the human phenotype in its behavioural aspect. This identification of culture with the behavioural phenotype paves the way for biology, as it were, to 'go underground'. Rather than referring to phenotypic traits that all humans have in common, it comes to be identified with the genotype, the inner programme at the heart of each human organism, hidden away in the nucleus of every cell of the body.

The source of the genotype/phenotype dichotomy lies in the Darwinian theory of variation under natural selection, augmented in the so-called 'modern synthesis' of twentieth century biology through an alliance with population genetics. The logic of the theory rests on the assumption that elements of the genotype alone can be passed from one generation to the next. And it is the genotype that is supposed to evolve through changes in the frequency of its information-bearing elements, the genes. The formation of the phenotype, by contrast, plays no part in the evolutionary process; it is confined within the life-cycle of each individual organism, beginning with its conception and ending with its death. Thus the notion that culture is phenotypic whereas biology is genotypic takes us to the fourth of the senses of 'biological' listed above: the sense that equates biology with a Darwinian (or more strictly, neoDarwinian) perspective.

Once, however, biology comes to be identified with the genes, or more specifically with genetic inheritance, the way is opened for an alternative view of culture, not as phenotypic behaviour, but as an underlying programme for behaviour, analogous to the genetic programme but transmitted by an alternative mechanism of inheritance namely, social learning. Hence we arrive at the fifth and final sense of the 'biological' in our list, referring to genetic as opposed to learning-transmitted influences on behaviour. Now it is not just 'biology' that has gone underground, but culture also. A distinction is introduced between culture and behaviour, the former referring to underlying rules and instructions (analogous to the genetic programme), the latter to their outwardly observable effects. To emphasise the analogy with genes, many writers have taken to calling the elements of transmitted culture by the term 'memes' - a term coined by biologist and popular science writer Richard Dawkins. ${ }^{19}$ Thus the 
human being receives, down the line from its ancestors, one set of genetically transmitted programme elements (genes), and another set of learning-transmitted programme elements (memes). And when the 'statement on race' ends by opposing 'cultural characteristics' to 'genetic inheritance', it draws directly on this notion of culture as intergenerationally transmitted information.

Looking at the whole passage from the 'statement on race', it should now be clear not only that it appeals to several notions of the biological or physical, but also that it continually shifts the goal-posts as regards the definition of culture. First culture is identified as a property of groups (as opposed to individuals), then it becomes a property of individuals (referring to attributes in which they differ rather than those they have in common), and finally it is identified with particles of heritable information that individuals are supposed to carry in their heads, analogous to the genes they carry in their bodies. It is possible to correlate these shifts, albeit rather roughly, with three ways of thinking about the distinction - and the relation - between biology and culture, that have characterised successive phases in the history of anthropology. I call these the Enlightenment phase, the Consensual phase and the Interactionist phase. In what follows, I shall first outline each of these phases, and then go on to conclude by suggesting how a focus on human development might at last allow us to move beyond the distinction between biological and cultural dimensions of human existence.

\section{From civilisation to consensus}

The Enlightenment phase, dating from the middle of the eighteenth century, was founded on the doctrine of the 'psychic unity of mankind', according to which all humans are alike in their basic potentials but differ in the degree to which these potentials are realised. From this point of view the biological part of man, otherwise known as 'human nature', constitutes a universal baseline for cultural development that has taken humanity from its primitive hunter-gatherer past to modern science and civilisation. This was Edward Tylor's view, as set out in his monumental Primitive Culture of 1871. It is important to stress that although Tylor was indubitably ethnocentric, in judging every culture by the standards of western civilisation and in placing his own society unequivocally at the top of the scale, he was not - or at least not yet - racist in his views. Primitive people, he thought, had all the necessary capacities to enable them to be civilised, but these capacities remained unfulfilled.

A decade later, however, following the publication of Darwin's The Descent of Man, Tylor changed his mind. Darwin had argued that culture could only be as advanced as the brains that produce it. The brains of 'civilised nations', he thought, were superior to those of 'barbarous tribes', in the same measure that the latter were superior to the brains of apes. Thus there was no way in which the savage could be educated into civilisation, since his brain simply wasn't big enough to accommodate it. Some advocates of so-called 'social Darwinism' went so far as to argue that, since primitive peoples were destined to lose out in the struggle for existence, the best way to promote the advance of human civilisation was to do everything possible to hasten their demise. This is not, it should be said, a position with which Darwin himself 
concurred. Yet it continued to resurface, notably in the eugenics movement, which sought to improve the human race through controlled breeding. ${ }^{20}$

It was against this background that anthropologists of the early twentieth century, particularly in the United States, reasserted the independence of culture and race. In 1917 one of the leading anthropologists of the day, Alfred L. Kroeber, published a paper under the title 'The Superorganic', that established what was to be the anthropological orthodoxy for years to come. ${ }^{21}$ Kroeber insisted that cultural phenomena were 'superorganic' in the sense that they existed on a distinct and higher plane of reality with emergent properties of its own. Racial categories could only apply to human beings as biological organisms; they had no purchase on the superorganic world. Today Kroeber's work, once enormously influential, is all but forgotten - not because his views are no longer accepted but because what needed to be spelled out explicitly then is nowadays part of what most anthropologists simply take for granted. But the reaction, in early twentieth century American anthropology, was not only against racism; it was also against the doctrine of evolutionary progress - the idea that the peoples of the world could be ranked on a single scale of absolute advance. Against this, Kroeber and his contemporaries argued that cultures could not be ranked higher or lower on any single scale; they were simply different. And these differences were thought to be imprinted upon a common substrate of biological universals. 'Man', Kroeber wrote, is 'a tablet that is written upon': nature provides the tablet, culture the message that is written. ${ }^{22}$

That, then, is the foundation for what I call (following Clifford Geertz) the consensual view of the distinction between human biology and culture. ${ }^{23}$ In this view, the essence of human nature was to be found not by stripping away the accumulated achievements of culture to reveal the natural man beneath, but rather by factoring out behavioural traits that are apparently common to all human groups. Those traits, for example, that are shared by the Scots, the Japanese and the Australian Aborigines belong to nature, those traits that differ from one group to another belong to culture. Note that this is not equivalent to saying that the Australian Aborigine is somehow closer to nature than the Scotsman. It is not a matter of having more or less culture, or of culture having reached different degrees of development. It is simply a matter of the inscription of different cultural messages upon the same basic substrate. Human nature no more constrains cultural form than paper constrains what you write on it.

\section{Interaction and development}

Kroeber was writing during the heyday of the so-called nature-nurture controversy - a controversy that was originally formulated in these terms by Darwin's cousin, Francis Galton. In 1874, Galton had published an influential book entitled Engish men of science: their nature and nurture, which purported to show that scientific genius was innate, and could not be accounted for in terms of the quality of upbringing. ${ }^{24}$ Others took up the argument on the side of nurture, arguing that the conditions of upbringing were everything, and that heredity could account for nothing at all. Though the debate has carried on furiously for decades, most biologists and anthropologists now take the view that behaviour cannot be described as one thing or the other, as due to either nature or nurture. Rather, they say, every instance of behaviour has to be seen as the 
product of a continuing interaction between the components of heredity (nowadays known as 'genes') and the environmental conditions of development. This means that we cannot simply factor out human behaviour, or for that matter the behaviour of any other creature, into its innate and acquired components.

Consider, for example, the work of the beaver. In his paper on 'The Superorganic', Kroeber had compared the feats of the beaver, in constructing dams, with those of human builders. His conclusion was that although the beaver's dam may be as impressive as many a human construction, the beaver and the human achieve their results by fundamentally different means: the former by instinct, the latter by learning. 'Who would be so rash', Kroeber asked rhetorically, 'as to affirm that one generation or a hundred or ten thousand of example and instruction would in the least convert the beaver from what he is into a carpenter or a bricklayer - or, allowing for his physical deficiency in the lack of hands, into a planning engineer? ${ }^{25}$

Some fifty years later, in a paper published in 1964 entitled 'The impact of the concept of culture on the concept of man', ${ }^{26}$ Clifford Geertz returned to the beaver/human comparison. But there was a significant difference. For Geertz recognises that the beaver's behaviour is not determined by nature rather than nurture, but is rather the product of an interaction between the two. Accordingly, I take Geertz's paper as representative of the third phase in the history of anthropological thinking about the biology/culture interface: what I call the interactionist phase. Let me quote the relevant passage:

Beavers build dams, birds build nests, bees locate food, baboons organise social groups, and mice mate on the basis of forms of learning that rest predominantly on the instructions encoded in their genes and evoked by appropriate patterns of external stimuli: physical keys inserted into organic locks. But men build dams and shelters, locate food, organise their social groups or find sexual partners under the guidance of instructions encoded in flow charts and blueprints, hunting lore, moral systems and aesthetic judgements: conceptual structures moulding formless talents. ${ }^{27}$

Thus beavers learn to build dams and humans learn to build shelters. But the form of learning in each case is significantly different.

In the case of the beaver, learning consists in the way in which given, genetically prescribed potentials are 'brought out', within the lifetime of the individual, by appropriate environmental stimuli. What the beaver inherits, with its genes, is not dam-building behaviour but a programme of instructions for the development of dambuilding, which nevertheless depends for its realisation on specific environmental conditions. Human beings, by contrast, do not inherit - in the genes - a programme for the development of house building. Rather, they inherit a capacity to acquire such programmes. To put it another way, the programme for the development of the human organism in its environment is genetically underdetermined. It has to be completed through the acquisition of additional instructions. And these instructions are encoded in what is commonly called culture, a body of information that is transmitted across the generations by non-genetic means. In short, for human beings there is not just one 
channel of inheritance but two. There is the genetic channel, shared with other animals such as the beaver. But there is also a separate, cultural channel. And human behaviour has to be understood as the result of a three-way interaction between both culturally and genetically transmitted information and the environment. ${ }^{28}$

Advocates of the interactionist view often claim that they have long since dispensed with the dichotomy between nature and nurture, or between the innate and the acquired. But in fact they have not. The dichotomy is still there, but has simply gone underground. Instead of dividing overt behaviours into those that are innate (such as the smile) and those that are acquired (such as the handshake), the division is made on the level of underlying instructions - between innate and acquired components of the programmes that guide all behaviour. The behaviour itself is understood as the consequence of an ongoing interaction between the two, under given environmental circumstances.

\section{Towards a relational approach}

I am not myself content with this way of thinking. I do not believe it makes any more sense to reduce biology to genes than it does to reduce culture to analogous units of information ('memes') that inhabit the mind. For in reality, what people do is not merely the effect of genetic, cultural and environmental causes. Genes and culture do not interact with the environment, nor are people and their behaviour the products of such interaction. If we ask what interacts with the environment, the answer is the people themselves. And through such interaction, people actively intervene in shaping the conditions of future development, both for themselves and for others. That is to say, people are the producers as much as the products of their own history, in a continuous process of social life.

Let me return for a moment to Clifford Geertz. 'One of the most significant facts about us', he writes, in the same paper to which I referred earlier, 'may finally be that we all begin with the natural equipment to live a thousand kinds of life but end in the end having lived only one'. ${ }^{29}$ Human life, in this view, is conceived as a movement from the universal to the particular, or from biology to culture, entailing a gradual 'filling up' of capacities and 'closing down' of possibilities. I can only conclude that such a view is fundamentally mistaken. The fact is that our bodily equipment, if we can call it that, is not ready-made but undergoes continual formation in the course of our lives. Even the skeleton, for example, grows in a body that is actively doing things, and its precise form is liable to bear the mark of these activities. And the growth of the body is an aspect of the very same developmental process by which we gain proficiency in the particular kind of life that we lead. So what $d o$ we begin with? What is already in place at the moment of inauguration of a new human life-cycle? The answer is not just a set of genes but a whole system of relations comprised by the presence of the fertilised egg with its complement of DNA, in a womb, in the body of a mother-to-be, who is in turn alive and active within a particular environment. In short, what each of us begins with is a developmental system. ${ }^{30}$

Human beings, then, are not born biologically or psychologically identical, prior to their differentiation by culture. There has to be something wrong with any explanatory 
scheme that needs to base itself upon the manifestly ludicrous claim - in the words of the evolutionary psychologists John Tooby and Leda Cosmides - that 'infants are everywhere the same'. ${ }^{31}$ Even parents of identical twins know this to be untrue! The source of the difficulty lies in the notion that culture is an extra ingredient that has to be 'added in' so as to complete the human being. In reality, all those specific abilities that have classically been attributed to culture - to walk in a certain way, to speak a certain language, to sit or squat, and so on - are incorporated, through processes of development, as properties of human organisms. In that sense, they are fully biological. But - and this is the really crucial point - biological differences are not genetic. In themselves, genes make no difference. They only make a difference in the context of the life histories of whole human beings, indissolubly body and mind, growing up and, in turn, raising their successors, in a particular environment. ${ }^{32}$

Clearly we have a major problem with 'biology' when it comes to human beings. At the root of the problem is our obsession with the idea that for every individual human being there must be something fixed and stable, which is present right from the moment of conception and that remains unchanged for the entire duration of the life cycle. Regardless of what happens to the individual in question, and of what he or she does, it is always supposed to be there. Most often, when people in modern western societies speak of human biology, they do not mean the scientific study of human organisms; they mean this constant thing that is supposed to reside inside each one of us, somehow orchestrating our growth and development. Much of our fascination with genes lies in our understanding that they do indeed remain (virtually) fixed and unchanging for every individual throughout life. Thus they seem to provide concrete proof of the existence of the individual human essence that we had always imagined. No wonder, then, that we jump to the conclusion that our biology must lie in the genes, and therefore that it is the genes that make us what we are.

When, some years ago, scientists claimed finally to have unravelled the human genome, we were all told on television and radio, and in the newspapers, that we were witnessing the birth of a totally new era in human understanding, on a par with the discovery of fire or the invention of the wheel. Presidents and heads of state literally queued up to pile on the rhetoric. Pundits proclaimed that our conception of ourselves, as human beings, would never be the same again. But within a few months all that was water under the bridge. For it soon turned out that the number of genes was simply too small to specify much of what makes a human being, and that most of these genes are anyway shared by all kinds of other creatures that could hardly be more different from ourselves, ranging from the mouse to the nematode worm. Now, the scientists proclaimed, they had made a new and even more radical discovery. Contrary to what had previously been thought, the genes do not make us what we are. Instead, we were told, the environment plays a decisive role in shaping human nature.

How depressingly familiar all of this sounds! Far from ushering in a radically new conception of ourselves, contemporary science has been rehearsing a nature-nurture debate that has been around, in one form or another, for centuries. The much vaunted human genome project, for example, rests on a central idea, namely that there is such a thing as a human genome - in other words, that a context-independent, hereditary specification of the essential form of humanity actually exists. This idea was well 
established long before science in a recognisably modern form ever got off the ground. If it continues to dominate our thinking about the advance of human selfunderstanding, it is not because it represents the peak of scientific achievement, but because it is deeply embedded in the institution of science itself. So long as it persists, moreover - so long, that is, that the notion of genetic inheritance is wedded to an essentialist definition of the human sub-species - the spectre of race will not go away.

My argument has been that in order to exorcise the spectre we need to wrest biology away from the stranglehold of geneticism, and to adopt instead a relational approach that focuses on the emergent and dynamic properties of developmental systems. To do so, we must acknowledge that our humanity is not naturally given as a hereditary endowment but is an ongoing historical project - or rather, a whole ensemble of such projects - that we have to work at. And we have to recognise that every one of us is forged in our organic being within this ensemble and plays his or her part in moving it along. Indeed behind the scenes, away from the razzmatazz of media hype and billion dollar research contracts, a number of biologists, anthropologists and philosophers have been laying the foundations for just such an approach. ${ }^{33}$ This is work that is actually set to revolutionise the way we think about ourselves, and I am optimistic that it will eventually prevail. Only then, however, can the spectre of race finally be laid to rest.

\footnotetext{
${ }^{1}$ Paper presented at the symposium What is special about the gene?, Cardiff University, $11^{\text {th }}$ September 2007

${ }^{2}$ Department of Anthropology, University of Aberdeen, UK, tim.ingold@abdn.ac.uk

${ }^{3}$ See, for example, P. Descola \& G. Palsson eds. 1996. Nature and Society: Anthropological Perspectives. London: Routledge; T. Ingold. 2000. The Perception of the Environment: Essays on Livelihood, Dwelling and Skill. London: Routledge; K. Milton. 2002. Loving Nature: Towards an Ecology of Emotion. London: Routledge; A. Roepstorff, N. Bubandt \& Kalevi Kull eds. 2003. Imagining Nature: Practices of Cosmology and Identity. Aarhus: Aarhus University Press.

${ }^{4}$ For an authoritative treatment of this history, see G. W. Stocking. 1968. Race, Culture and Evolution. New York: Free Press.

${ }^{5}$ A recent discussion of these issues is P. Wade. 2002. Race, Nature and Culture: An Anthropological Approach. London: Pluto Press. In addition, the journal American Ethnologist recently carried a forum discussion on the theme of 'genomics and racialization' (American Ethnologist 2007; 34(2): pp. 210 251).

${ }^{6}$ See P. M. Graves-Brown. “The Ghost of Cain?” Neanderthals, Racism and Speciesism. Antiquity 1996; 70: 978-981.

${ }^{7}$ See G. W. Stocking. 1968. Race, Culture and Evolution. New York: Free Press, pp. 265-6; T. Ingold. 1986. Evolution and Social Life. Cambridge: Cambridge University Press, pp. 54-55, 381 fn. 14.

${ }^{8}$ Modern anthropology's concept of culture has, of course, been subjected to extensive critique over the last two decades. It is debateable how many sociocultural anthropologists would still subscribe to the view that humanity comprises a mosaic of distinct cultures. However the contemporary critique of modernism has tended to exacerbate the split between the 'biological' and 'sociocultural' divisions of anthropology. By and large, the few sociocultural anthropologists who continue to seek a rapprochement with biological approaches in the discipline remain committed to the modernist paradigm, as do biological anthropologists themselves. This commitment is commonly defended in the name of Science, against what is (rightly or wrongly) perceived as a militantly anti-scientific, postmodern humanism. It is no surprise, then, that the post-modern critique of the culture concept has so far had little purchase on anthropological endeavours to reintegrate 'biology' and 'culture'. In the context of these endeavours, 'culture' is still taken to mean much the same as what it meant to the anthropology of fifty years ago.
} 
${ }^{9}$ E. Wolf. Perilous Ideas: Race, Culture, People. Current Anthropology 1994; 35(1): 1-12, p.1.

${ }^{10}$ Ibid., p. 4.

${ }^{11}$ On the misapplication of intelligence testing regimes in cross-cultural contexts, see M. Cole. 1996. Cultural Psychology: A Once and Future Discipline. Cambridge, Mass.: Harvard University Press (Belknap), pp.52-7.

${ }^{12}$ Among the most notorious of recent examples was R. Herrnstein and C. Murray. 1994. The Bell Curve: Intelligence and Class Structure in American Life. New York: Free Press.

${ }^{13}$ F. Boas. 1940. Race, Language, and Culture. New York: Free Press, p. 165.

${ }^{14}$ American Association of Physical Anthropologists. AAPA Statement on Biological Aspects of Race. American Journal of Physical Anthropology 1996; 101: 569-70; also available at http://www.physanth.org/positions/race.html.

${ }^{15}$ See T. Ingold. An Anthropologist Looks at Biology. Man (N.S.) 1990; 25: 208-29, pp. 217-18.

${ }^{16}$ That is why, when biologists do speak of collectivities of one kind or another, they commonly have resort to the notion of 'population'. The population is understood as an aggregate of discrete individuals, rather than as a group per se.

${ }^{17}$ On the debate in American anthropology between those who saw culture as a property of individuals and those who saw it as a property of groups, see Ingold, op. cit., note 7, pp. 230-6. The principal protagonists were Franz Boas on the former side, and Alfred Kroeber on the latter.

${ }^{18}$ On the origin of this distinction and its impact on the history of twentieth-century biology, see G. Gudding. The Phenotype/Genotype Distinction and the Disappearance of the Body. Journal of the History of Ideas 1996; 57(3): 525-45.

${ }^{19}$ See R. Dawkins. 1976. The Selfish Gene. Oxford: Oxford University Press. The novelty of Dawkins's idea has been hugely exaggerated. Similar proposals have been made, on and off, for decades (these are reviewed in Ingold, op. cit., note 7, pp. 362-4). Outside the realms of advertising, perhaps the best evidence for the idea of the meme as a cultural replicator lies in the success with which the idea itself has caught on (see A. Costall. The 'meme' meme. Cultural Dynamics 1991; 4(3): 321-335). It has not, however, had much success in anthropology, least of all among social and cultural anthropologists, most of whom find the idea repellent. Biological anthropologists have given it somewhat greater credence (see, for example, R. Aunger. 2002. The Electric Meme: A New Theory of How We Think and Communicate. New York: Free Press). It is undoubtedly among cognitive psychologists, however, that it has been most positively received (see S.J. Blackmore. 1999. The Meme Machine. Oxford: Oxford University Press).

${ }^{20}$ See E.B. Tylor. 1871. Primitive Culture (2 vols.). London: John Murray; C. Darwin 1874. The Descent of Man and Selection in Relation to Sex ( $2^{\text {nd }}$ edition). London: John Murray. On the differences between Tylor and Darwin concerning the educability of 'savages', and Tylor's change of heart, see Ingold, op. cit., note 7, pp. 57-8. It is shocking to find that at late as 1972, one of the leading biologists of the day, C.D. Darlington, could still argue - in a lecture published by a prestigious academic press - that the ranking of classes in modern societies corresponds to hereditary differences in intellectual ability and should be preserved in the interests of civilisation. See C.D. Darlington. 1972. Race, Class and Culture, in J.W.S. Pringle (ed.) Biology and the Human Sciences. Oxford: Clarendon Press.

${ }^{21}$ A.L. Kroeber. The Superorganic. American Anthropologist 1917; 19: 163-213.

${ }^{22}$ ibid., p. 179.

${ }^{23}$ Geertz refers to it by the notion of consensus gentium. See C. Geertz 1973. The Interpretation of Cultures. New York: Basic Books, pp. 37-43.

${ }^{24}$ F. Galton. 1874. English Men of Science: Their Nature and Nurture. London: Macmillan.

${ }^{25}$ Kroeber, op. cit., note 21, p. 176.

${ }^{26}$ The paper is reprinted as Chapter 2 of Geertz, op. cit., note 23.

27 ibid.: pp. 49-50.

${ }^{28}$ This is the foundation for the so-called dual inheritance model of gene-culture co-evolution. See P. J. Richerson \& R. Boyd. A Dual Inheritance Model of Human Evolutionary Process, I: Basic Postulates and a Simple Model. Journal of Social and Biological Structures 1978; 1: 127-54; C.J. Lumsden \& E.O. Wilson. 1981. Genes, Mind, and Culture. Cambridge, Mass.: Harvard University Press; W.H. Durham. 1991. Coevolution: Genes, Culture and Human Diversity. Stanford: Stanford University Press.

${ }^{29}$ Geertz, op. cit., note 23, p. 45. 
${ }^{30}$ On the concept of the developmental system, see S. Oyama. 1985. The Ontogeny of Information: Developmental Systems and their Evolution. Cambridge: Cambridge University Press. On the application of the concept within anthropology, see T. Ingold 2000. From Complementarity to Obviation: On Dissolving the Boundaries Between Social and Biological Anthropology, Archaeology and Psychology, in S. Oyama, P.E. Griffiths \& R.D. Gray (eds.) Cycles of Contingency: Developmental Systems and Evolution. Cambridge, Mass: MIT Press, pp. 255-279.

${ }^{31}$ J. Tooby \& L. Cosmides. 1992. The Psychological Foundations of Culture. In J.H. Barkow, L. Cosmides and J. Tooby (eds.) The Adapted Mind: Evolutionary Psychology and the Generation of Culture. New York: Oxford University Press, p. 33.

${ }^{32}$ T. Ingold. 2000. Evolving skills. In H. Rose \& S Rose (eds.) Alas Poor Darwin: Arguments Against Evolutionary Psychology. London: Jonathan Cape, New York: Random House, pp. 225-246.

${ }^{33}$ It would be more accurate, perhaps, to say that a number of approaches are currently being pursued, which have in common a concern to rebalance the relation between evolutionary and developmental processes, away from the strict subordination of the latter to the former that is characteristic of contemporary neo-Darwinism. The approach with which I am most familiar, and to which I have myself contributed, is that of the 'developmental systems theory' (DST) of Susan Oyama and her colleagues. For a representative sample of work in DST across a wide interdisciplinary field including evolutionary and developmental biology, ethology and ecology, psychology, anthropology and philosophy - see S. Oyama, P.E. Griffiths \& R.D. Gray, eds. 2000. Cycles of Contingency: Developmental Systems and Evolution. Cambridge, Mass: MIT Press. For other approaches, see, inter alia, M-W. Ho \& P.T. Saunders, eds. 1984. Beyond Neo-Darwinism: Introduction to the New Evolutionary Paradigm. London: Academic Press; B.C. Goodwin, A. Sibatani \& G.C. Webster, eds. 1989. Dynamic Structures in Biology. Edinburgh: Edinburgh University Press; S.A. Kauffman. 1993. The Origins of Order: Self-Organization and Selection in Evolution. Oxford: Oxford University Press; H. Maturana and F. Varela 1973. Autopoiesis and Cognition: The Realization of the Living, eds. R. S. Cohen and M. W. Wartofsky. Dordrecht: D. Reidel; S.B. Carroll. 2005. Endless Forms Most Beautiful: The New Science of Evo Devo and the Making of the Animal Kingdom. New York: Norton; E. Jablonka \& M. J. Lamb. 2005. Evolution in Four Dimensions: Genetic, Epigenetic, Behavioral, and Symbolic Variation in the History of Life. Cambridge, Mass: MIT Press. 